British Journal of Psychiatry (1988), 152, 711-724

\title{
Correspondence
}

\author{
Editor: Greg Wilkinson
}

Contents: Assaults on staff by psychiatric in-patients/ Monitoring problem drug use/ECT in parkinsonism with affective disorder/Failure to convulse with ECT/Chronic schizophrenia and long-term hospitalisation/Incest and anorexia nervosa/Compensation psychosis/Research in psychotherapy/Mania in the early stages of AIDS/Time and the dopamine hypothesis/Late paraphrenia/Lithium, imipramine and hydroxytryptophan in resistant depression/ Two-stage screening/Khat-induced paranoid psychosis/Down's syndrome with mania/Dangerous delusions: the 'Hollywood phenomenon'/Calcium therapy for neuroleptic-induced extrapyramidal symptoms.

\section{Assaults on Stafi by Psychiatric In-Patients}

SIR: Haller \& Doherty (Journal, February 1988, 152, 174-179) raise valid points on the difficulties inherent in accurately predicting violent behaviour by psychiatric patients.

Over-prediction of violence, with resultant detention of many non-violent individuals, is the price society is prepared to pay for protection. More accurate methods of prediction would reduce this overkill. However, statistical accuracy would be considerably improved if all individuals were predicted non-violent, but this would be unacceptable as a few are dangerous.

From my experience, the vast majority of violent incidents within mental hospitals are perpetrated by a very small percentage of individuals (Fottrell, 1980). In the first instance, attention should be focused on persistent offenders who inflict personal physical injury. Damage to property and abuse may have different determinants. When examining correlations and standardising for variances, it is crucial to heed the role of the victim and the effect on the perpetrator of labelling him 'violent'. Victims of patient violence, especially non-impulsive violence, may have a role not only in provoking the incident consciously or subconsciously, but also to a degree in determining the form and seriousness of the act.

Rubin (1972) commented that society has a way "of labelling some mentally ill as criminals, over- predicting violence and then acting on that prediction to exact retributive costs". He continued, "the poor, the mentally ill, the drifter and the black are very likely to be labelled in this way for social reasons unrelated to any violent behaviour, but rather to society's need to find objects who represent projections of its own violence".

Scheff (1963) wrote persuasively on the consequences of labelling and described categorising in this context as the single most important cause of "a career of individual deviance". Further research is urgently needed on this complex prediction problem.

E. FotTrReLL

Psychogeriatric Department

Tooting Bec Hospital

London SWI7 8BL

\section{References}

FotTRELL, E. (1980) A study of violent behaviour among patients in psychiatric hospitals. British Journal of Psychiatry, 136, 216-221. RuBIN, B. (1972) Prediction of dangerousness in mentally ill criminals. Archives of General Psychiatry, 27, 397-407.

SCHEFF, T. J. (1963) Decision rules, types of error, and their consequences in medical diagnosis. Behavioural Science, 8, 97-107.

\section{Monitoring Problem Drug Use}

SIR: Parker et al (Journal, February 1988, 152, 214-221) conclude on the basis of their experience in Bristol that case-register surveys concentrating on information from GPs, psychiatrists, accident and emergency departments, the Home Office, and probation officers are the most cost-effective method of estimating and monitoring the prevalence of problem drug use. Our recent experience in Oxford City (Peveler et al, 1988) differs from theirs. In our survey of the prevalence of opioid misuse, GPs and psychiatrists notified over $40 \%$ of the total sample, and probation officers contributed $18 \%$, while the Home Office register and accident and emergency departments did not contribute significantly. It is difficult to see how the Home Office notifications, which are supplied by doctors, can add to the total. In our study the low referral rate from the accident and emergency department was expected, because it is not located in the city centre, and is known to 
operate a strict non-prescribing policy. A significant proportion of our notifications were provided by "non-statutory" sources such as voluntary agencies and drug users themselves. Although multisource enumeration methods are expensive and timeconsuming, they demonstrate the independence of different sources of information. The value of individual sources for continued monitoring varies from place to place and from time to time, according to patterns of local service provision and the views of the users themselves about the value of the different agencies. Local knowledge is vital for making choices about which agencies reflect trends most accurately, and choices may need to be revised as patterns of service use change over time.

University Department of Psychiatry

\section{ROBERT PEVEler}

Warneford Hospital

Oxford

\section{Reference}

Peveler, R. C., Green, R. \& Mandelbrote, B. M. (1988) The prevalence of heroin misuse in Oxford City. British Journal of Addiction (in press).

\section{ECT in Parkinsonism with Affective Disorder}

SIR: The paper by Atre-Vaidya \& Jampala (Journal, January 1988, 152, 55-58) is a most interesting contribution to, but not a complete solution of, the problem of the effectiveness of ECT in these conditions. Sometimes parkinsonism responds; sometimes depression responds; sometimes both respond; sometimes neither responds.

I have made observations on five patients who were referred to me for ECT for severe depression, who also had independently-made diagnoses of Parkinson's disease, and who had not recently received levodopa or anti-psychotic drugs. As well as clinical observation, several rating scales were used, before treatment and after treatment. Memory was rated by the Mental Status Questionnaire (Kahn et $a l, 1960)$ and the forward digit span of the Wechsler memory sub-scale (Wechsler, 1965). Depression was rated on the Hamilton scale (Hamilton, 1960). Parkinsonism was rated on the Simpson Angus scale (Simpson \& Angus, 1970), and the Webster scale (Webster, 1968).

Treatments were right unilateral, with electroencephalographic recording of adequate seizure activity. In three cases parkinsonism and depression both improved. In one case parkinsonism was not usefully improved (although improved on rating scales), but depression improved. One patient, previously bedridden by parkinsonism, became mobile enough to walk to a window and try to jump out. Her depression was not improved usefully, even after nine treatments.

By the fourth treatment, the Simpson-Angus scores had improved in all cases. By the fifth treatment the Webster scale had improved in all cases. Memory worsened temporarily in one case, and improved in the others.

At follow-up, improvement in parkinsonism is maintained four years later in one patient; it relapsed in one month in one patient and at one to two months in two others. Follow-up is incomplete in one.

\section{Peter Birkett}

2 Copeland Drive

Suffern, New York 10901

USA

\section{References}

HamiLton, M. (1960) A rating scale for depression. Journal of Neurology. Neurosurgery, and Psychiatry, 23, 56-59.

Kahn, L. K., Goldfarb, A. J., Pollack, M. \& Peck, A. (1960) Brief objective measures for the determination of mental status in the aged. American Journal of Psychiatry, 117, 326-328.

SiMPSON, G. \& ANGUS, J. W. S. (1970) Drug induced extrapyramidal disorders. Acta Psychiatrica Scandinavica, Suppl. 212, 11-19.

WeBsTER, D. D. (1968) Critical analysis of the disability in Parkinson's disease. Modern Therapeutics, 5, 257-282.

WECHSLER, D. (1945) A standardized memory scale for clinical use. Journal of Psychology, 19, 87-95.

\section{Failure to Convulse with ECT}

SIR: Whatever the constitutional or other factors involved, failure to convulse with ECT, as described by Sharpe \& Andrew (Journal, January 1988, 152, 134-136), indicates an inadequate or inefficient type of stimulus for that patient.

Since the patient resistance is unknown, but probably between 200 and 500 ohms, the stimulus E2 with Ectron Duopulse IV on setting 2 would have given a dosage of between 215 and $416 \mathrm{mC}$; El on setting 1 of between 328 and $683 \mathrm{mC}$. In both cases the duration is $1.7 \mathrm{~s}$. The last $4 \mathrm{~ms}$ of each semi-sine wave is largely ineffective because of falling potential, so that the effective stimulus is 108-208 $\mathrm{mC}$ (E2), and 164-342 mC (El).

With stimulus $\mathrm{T}$ (Transpsycon on $50 \mathrm{~J}$ setting) the output is between 336 and $540 \mathrm{mC}$ in about $1.25 \mathrm{~s}$. Owing to the rapid exponential fall of potential with this capacitor discharge type of apparatus the effective stimulus is limited to the first $0.5-0.75 \mathrm{~s}$.

The optimum parameter levels for ECT are still uncertain, but the above durations are probably too short, and the effective current too low, to induce seizures in every patient.

It is impossible to allow for all the variables, but the use of a constant current stimulus largely compensates for variation in the patient resistance. Most 